WSRC-TR-2003-00148, Rev. 0

SRT-RPP-2003-00063

KEYWORDS:

River Protection Project Laboratory

Technetium Eluate

Evaporation

Solubility

Physical Properties

RETENTION TIME:

0.1.1.1.1 Permanent

\title{
Technetium Eluate Evaporation Solubility And Precipitation Performance
}

Authors:

Issue Date:

Test Specification No.

Test Plan No.

Test Scoping Statement:
Jermaine D. Johnson, 773-A, SRTC, SRS

Robert A. Pierce, 773-A, SRTC, SRS

March 2003

24590-WTP-TSP-RT-01-009, Rev. 0

WSRC-TR-2002-00433, Rev. 0

S-82 
This document was prepared in conjunction with work accomplished under Contract No. DE-AC09-96SR18500 with the U. S. Department of Energy.

\section{DISCLAIMER}

This report was prepared as an account of work sponsored by an agency of the United States Government. Neither the United States Government nor any agency thereof, nor any of their employees, makes any warranty, express or implied, or assumes any legal liability or responsibility for the accuracy, completeness, or usefulness of any information, apparatus, product or process disclosed, or represents that its use would not infringe privately owned rights. Reference herein to any specific commercial product, process or service by trade name, trademark, manufacturer, or otherwise does not necessarily constitute or imply its endorsement, recommendation, or favoring by the United States Government or any agency thereof. The views and opinions of authors expressed herein do not necessarily state or reflect those of the United States Government or any agency thereof.

This report has been reproduced directly from the best available copy.

Available for sale to the public, in paper, from: U.S. Department of Commerce, National Technical Information Service, 5285 Port Royal Road, Springfield, VA 22161, phone: (800) 553-6847, fax: (703) 605-6900

email: orders@ntis.fedworld.gov

online ordering: http://www.ntis.gov/help/index.asp

Available electronically at http://www.osti.gov/bridge

Available for a processing fee to U.S. Department of Energy and its contractors, in paper, from: U.S. Department of Energy, Office of Scientific and Technical Information, P.O. Box 62, Oak Ridge, TN 37831-0062,

phone: (865)576-8401,

fax: (865)576-5728

email: $\underline{\text { reports@ adonis.osti.gov }}$ 


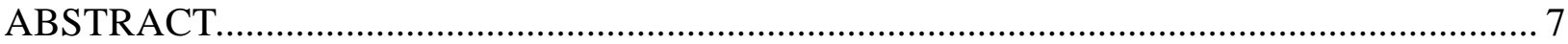

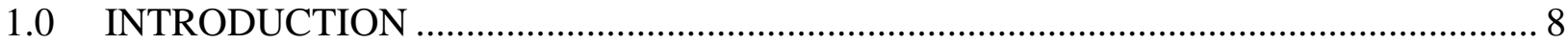

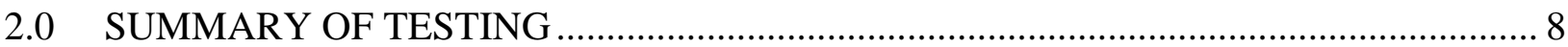

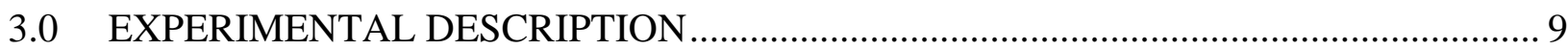

$3.1 \quad$ SIMULANT COMPOSITION ...........................................................................................................................

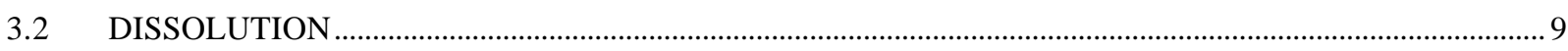

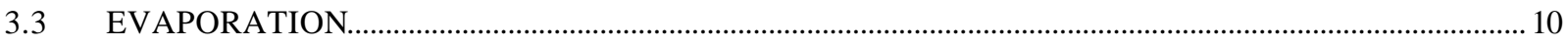

3.4 SINGLE AND DOUBLE COMPONENT SOLUBILITY............................................................................ 10

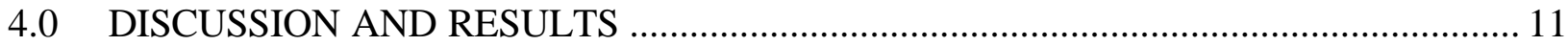

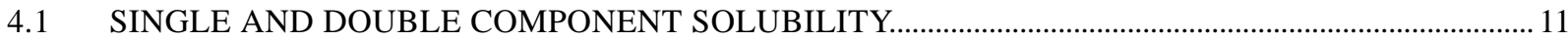

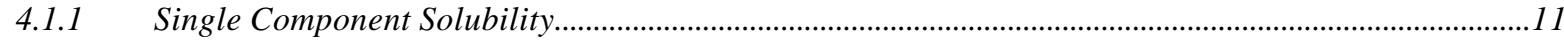

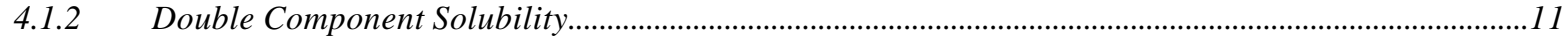

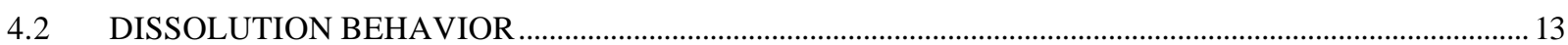

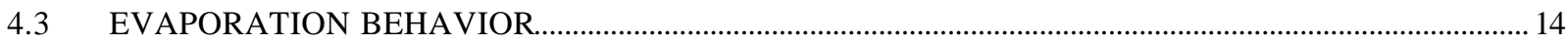

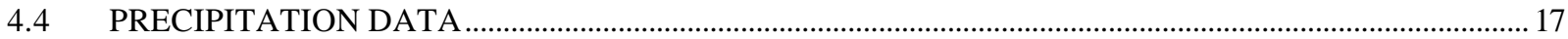

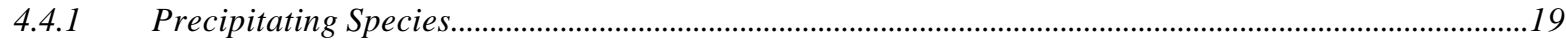

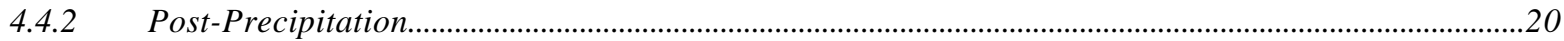

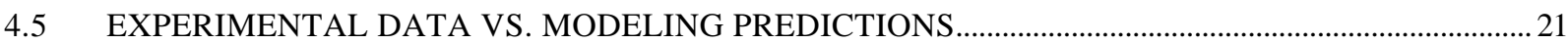

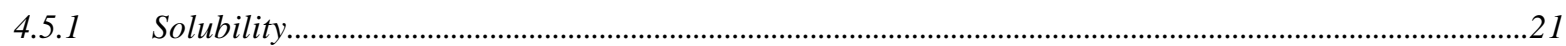

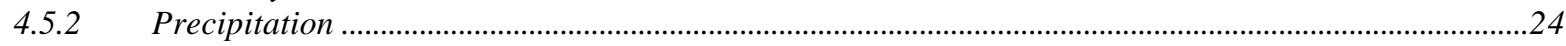

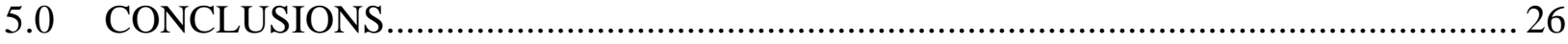

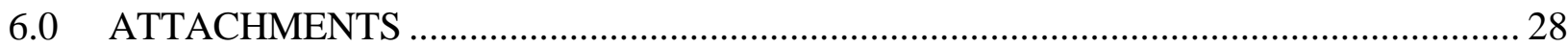




\section{LIST OF FIGURES}

FIGURE 4-1. TECHNETIUM ELUATE SINGLE AND DOUBLE COMPONENT SOLUBILITY....................................................... 12

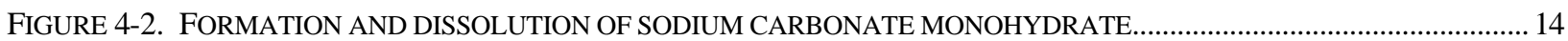

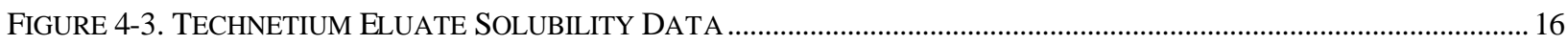

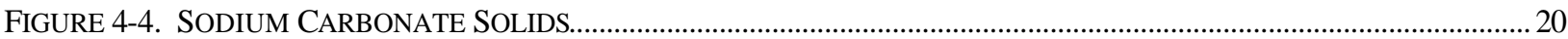

FIGURE 4-5. TECHNETIUM ELUATE PRECIPITATION AND SOLUBILITY …....................................................................23

\section{LIST OF TABLES}

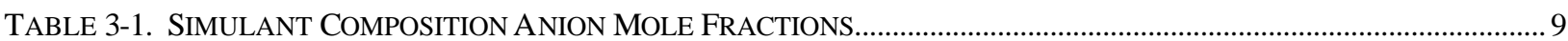

TABLE 3-2. SINGLE AND DOUBLE COMPONENT SOLUBILITY MATRIX ........................................................................ 10

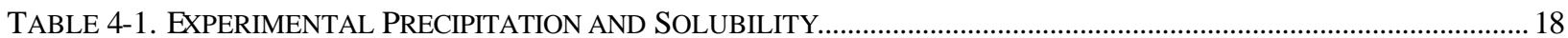

TABLE 4-2. EXPERIMENTAL PRECIPITANTS VS. MODELING PRECIPITANTS................................................................. 25

\section{ATTACHMENTS}

ATTACHMENT 1. PHYSICAL PROPERTY DATA

\section{LIST OF ACRONYMS}

$\begin{array}{ll}\text { LAW } & \text { Low Activity Waste } \\ \text { PNNL } & \text { Pacific Northwest National Laboratory } \\ \text { RPP } & \text { River Protection Project } \\ \text { SRTC } & \text { Savannah River Technology Center } \\ \text { WTP } & \text { Waste Treatment Plant } \\ \text { XRD } & \text { X-ray Diffraction }\end{array}$


SRT-RPP-2003-00063

\begin{abstract}
The baseline flowsheet for low activity waste (LAW) in the Hanford River Protection Project (RPP) Waste Treatment Plant (WTP) includes pretreatment of supernatant by removing technetium using ion exchange. The ion exchange column is loaded with IBC Company's Super Ligand ion exchange resins to separate technetium (Tc) from low-activity waste solutions. After the ion exchange column is loaded, the technetium will be eluted with water to allow the column to be conditioned for re-use. The technetium eluate solution will then be concentrated in a vacuum evaporator to minimize storage volume. The concentrated technetium eluate may later be blended with concentrated cesium eluate prior to transfer and additional processing.
\end{abstract}

The OLI Environmental Simulation Program is used to predict the solubility point of the feed solution and the precipitants during evaporation. The primary purpose of this work is validation of the predictions of this Tc eluate computer model. This will include validating the solubility predicted by the model and the solids formed upon precipitation and storage.

The experimental simulant compositions were given by points selected from the simulation design matrix; these points were chosen based on the simulation results. These simulants were produced, dissolved, evaporated to the solubility endpoint, and characterized at $20^{\circ} \mathrm{C}, 30^{\circ} \mathrm{C}, 45^{\circ} \mathrm{C}$, and $70^{\circ} \mathrm{C}$

In general there is agreement between the modeling and experimental results. However, there are some inconsistencies as described below. At $30^{\circ} \mathrm{C}$, there is an inconsistency between the experimental dissolution results as compared to both the modeling and experimental evaporation results. This is due to the transition from the decahydrate to the monohydrate form of sodium carbonate at $30^{\circ} \mathrm{C}$ (the monohydrate exists at higher tempertures). The monohydrate formed is more soluble than the decahydrate. However, heat is required for this transition to take place. Since there is no significant heating used during dissolution, it is doubtful that the monohydrate is formed. This was further demonstrated during singleand double-component solubility tests. Therefore, the evaporation and modeling trends exhibit a sharp increase in solubility at $30^{\circ} \mathrm{C}$ due to the formation of the monohydrate, while the dissolution curve is relatively flat at this temperature. If the $30^{\circ} \mathrm{C}$ matrix is removed from these curves, there is good agreement exhibited between the general shape of the evaporation and dissolution curves.

Additionally, the model accurately predicts the dissolution behavior of the simulants with in the $70^{\circ} \mathrm{C}$ matrix that do not contain oxalate. For the simulants that do not contain oxalate, the solubility values predicted by the model and that which is obtained through dissolution are relatively the same.

Solids found to precipitate in the experiment were compared to those predicted by the model. In the simulants that contain oxalate, the model predicts it as a precipitant for the $45^{\circ} \mathrm{C}$ matrix, while experimentation consistently yielded sodium carbonate as the precipitant. Also, at $20^{\circ} \mathrm{C}$, burkeite was found to precipitate experimentally, while the model predicted the precipitation of sodium sulfate. The model should be adjusted to reflect these experimental results 
SRT-RPP-2003-00063

\subsection{INTRODUCTION}

The baseline flowsheet for low activity waste (LAW) in the Hanford River Protection Project (RPP) Waste Treatment Plant (WTP) includes pretreatment of supernatant by removing technetium using ion exchange. The ion exchange column is loaded with IBC Company's Super Ligand ion exchange resins to separate technetium (Tc) from low-activity waste solutions. After the ion exchange column is loaded, the column will be eluted with water and the resin conditioned for re-use. The ion exchange resin is eluted after each cycle. The technetium eluate solution will then be concentrated in a vacuum evaporator to minimize storage volume. The concentrated technetium eluate may later be blended with concentrated cesium eluate prior to transfer and additional processing.

The OLI Environmental Simulation Program is used to predict the solubility of the feed solution and the precipitants during evaporation. The modeling efforts also predict solution characteristics at varying storage temperatures. Of central importance is identifying the effects of varying feed components on overall solubility. The point of solubility defines the upper limit of eluate evaporation and liquid storage temperature. The solubility point also defines the chemical and physical properties of the eluate at the end point. Physical property data may be an integral part of tracking evaporator operations as they progress toward their endpoint. Once the experimental data has been collected it will be used to validate or modify the predictions of the OLI modeling software.

The primary purpose of this work is validation of the predictions of the Tc eluate computer model. This will include validating the solubility points predicted by the model and the solids formed upon precipitation and storage. The experiments evaluated the concentrated eluates at four temperatures between $20^{\circ} \mathrm{C}$ and $70^{\circ} \mathrm{C}$ for the concentrated eluate: $20,30,45$, and $70^{\circ} \mathrm{C}$. Using simulant of compositions identical to those of several computer-generated technetium eluates, system behavior as a function of storage temperature will be evaluated from experimental data. Other parameters measured are density and viscosity.

\subsection{SUMMARY OF TESTING}

An experimental matrix of Tc eluate compositions was derived as a subset of the Tc eluate simulation design matrix. SRTC identified Tc simulants as a function of temperature within the matrix. The Tc eluate simulant solutions were based on simulations performed with the model. ${ }^{1}$ The evaporation model predicted the evaporation endpoint as well as the major precipitants for each simulant. Tc simulants were produced, dissolved, evaporated, and characterized at $20^{\circ} \mathrm{C}, 30^{\circ} \mathrm{C}, 45^{\circ} \mathrm{C}$, and $70^{\circ} \mathrm{C}$

Testing included the following activities:

1. Dissolution Experiments: Technetium eluate simulations consisted of up to nine dry chemical components. These simulations were dissolved in water. Once dissolution was achieved, the solubility points were recorded. The solubility points were then compared against modeling predictions.

2. Evaporation Experiments: The solutions generated during the dissolution portion of the experiment were used for evaporation. These solutions were evaporated until solids formed. The amount of water removed from the system was recorded and the solids were filtered and submitted for XRD analyses. The precipitation points and the type of solids precipitated were compared with model predictions.

\footnotetext{
${ }^{1}$ C. D. Barnes. "Preliminary Modeling Results of Evaporated Tc-Eluate Physical Properties," WSRC-TR2002-00319 Rev. 0
} 
SRT-RPP-2003-00063

3. Determination of Physical \& Chemical Properties: The Tc eluate solutions formed by dissolution of the chemical components and the precipitants formed during the evaporation process were characterized for physical and chemical properties. The solutions were characterized by density, viscosity, $\mathrm{pH}$, and ion chromatography measurements. The precipitants were characterized by $\mathrm{x}-$ analyses (XRD).

4. Single- and double-component solubility: These experiments tested the solubility of the individual components and of certain component pairs in $0.1 \mathrm{M} \mathrm{NaOH}$. This data was then compared against the data obtained from the multi-component test.

5. Compare and Correlate Experimental Data: As a primary purpose of this experiment, SRTC compared the experimental data obtained from testing with the predictions of the OLI evaporator model.

\subsection{EXPERIMENTAL DESCRIPTION}

\subsection{SIMULANT COMPOSITION}

Simulated technetium eluate solutions were composed of a combination of nine sodium salt components. A matrix of eighteen simulations was made with varying concentrations of these chemical components. The following chart depicts the salts used to develop the simulants and their mole fractions. The associated cations are potassium and sodium. The potassium, added as potassium hydroxide (KOH), composes 2.5 mole $\%$ of the cations. The other major cation is sodium, which composes 97.5 mole\% of the cations. Nonradioactive sodium perrhenate $\left(\mathrm{NaReO}_{4}\right)$ is added as a substitute for radioactive sodium pertechnitate $\left(\mathrm{NaTcO}_{4}\right)$. Aluminate $\left(\mathrm{AlO}_{2}\right)$ is formed by the interaction of aluminum nitrate with hydroxide.

Table 3-1. Simulant Composition Anion Mole Fractions

\begin{tabular}{|c|c|c|c|c|c|c|c|c|c|c|c|c|c|c|c|c|c|c|}
\hline \multicolumn{10}{|c|}{ ANION MOLE FRACTIONS } \\
\hline Simulation \# & 1 & 2 & 3 & 4 & 5 & 6 & 7 & 8 & 9 & 10 & 11 & 12 & 13 & 14 & 15 & 16 & 17 & 18 \\
\hline $\mathrm{AlO}_{2}$ & 2.8 & 0.7 & 2.4 & 2.8 & 1.7 & 2.8 & 2.8 & 2.9 & 0.8 & 2.8 & 1.9 & 2.8 & 2.9 & 2.7 & 2.8 & 2.7 & 2.9 & 0.7 \\
\hline $\mathrm{C}_{2} \mathrm{O}_{4}$ & 0.0 & 0.0 & 0.0 & 1.3 & 1.0 & 1.2 & 0.0 & 1.3 & 0.0 & 1.3 & 0.0 & 1.3 & 1.3 & 0.0 & 1.3 & 0.0 & 1.3 & 0.0 \\
\hline $\mathrm{CO}_{3}$ & 27.3 & 14.7 & 16.2 & 35.4 & 59.0 & 51.7 & 45.4 & 71.0 & 57.4 & 26.3 & 69.7 & 25.3 & 48.5 & 48.2 & 30.0 & 69.1 & 64.2 & 28.2 \\
\hline $\mathrm{NO}_{2}$ & 43.7 & 41.9 & 5.0 & 4.7 & 9.3 & 14.4 & 28.2 & 9.1 & 13.7 & 15.4 & 8.1 & 25.6 & 13.6 & 16.8 & 24.3 & 4.6 & 13.3 & 18.6 \\
\hline $\mathrm{NO}_{3}$ & 9.5 & 18.1 & 70.0 & 42.7 & 21.7 & 16.4 & 14.2 & 9.9 & 10.2 & 36.9 & 14.9 & 24.7 & 27.6 & 17.9 & 23.6 & 10.5 & 10.1 & 38.2 \\
\hline $\mathrm{OH}$ & 5.3 & 12.9 & 5.6 & 13.2 & 6.4 & 11.7 & 5.2 & 5.4 & 5.7 & 13.3 & 5.4 & 13.2 & 5.4 & 12.9 & 13.0 & 13.0 & 7.1 & 12.8 \\
\hline $\mathrm{SO}_{4}$ & 11.3 & 10.9 & 0.0 & 0.0 & 0.2 & 1.0 & 4.2 & 0.3 & 12.2 & 3.3 & 0.0 & 6.4 & 0.8 & 0.7 & 4.4 & 0.0 & 0.3 & 1.4 \\
\hline $\mathrm{TcO}_{4}$ & 0.0 & 0.7 & 0.8 & 0.0 & 0.8 & 0.7 & 0.0 & 0.0 & 0.0 & 0.7 & 0.0 & 0.7 & 0.0 & 0.7 & 0.7 & 0.0 & 0.7 & 0.0 \\
\hline
\end{tabular}

\subsection{DISSOLUTION}

A matrix of eighteen simulants was created for a range of storage temperatures $\left(20^{\circ} \mathrm{C}, 30^{\circ} \mathrm{C}, 45^{\circ} \mathrm{C}\right.$, and $70^{\circ} \mathrm{C}$ ) between 20 and $70^{\circ} \mathrm{C}$. A shaker bath was used for agitation and temperature control while dissolution was being conducted. Small amounts of water $(\sim 5 \mathrm{ml})$ were added step wise during the experiment. After the addition of water, the solutions were given at least 30 minutes to dissolve. If solids remained, more water was added in a similar manner until all solids were completely dissolved. The initial amount of water needed to dissolve the solids was based on model solubility predictions and a calculated final solution volume of $60 \mathrm{~mL}$. As the solids approached complete dissolution, the volume of water incrementally added was decreased. 
SRT-RPP-2003-00063

\subsection{EVAPORATION}

The evaporation portion of the test program was performed using the solutions generated from the dissolution experiments discussed in Section 3.2. The evaporation process began by removing the samples from the dissolution bath. Some of the samples were filtered due to indissolubility, which will be explained in subsequent sections (Section 4.2). After filtering, $5 \mathrm{~mL}$ of water were added to form unsaturated solutions. The caps of the containers were removed and the samples were heated.

The samples were heated in open air to evaporate water and initiate precipitation. Evaporation of the Tc simulants was done incrementally either on a hot plate or in a heated water bath. Since the samples dissolved at $20^{\circ} \mathrm{C}$ and $45^{\circ} \mathrm{C}$ were contained in glass flasks, hot plates were used for evaporation. The evaporation temperature for these samples was maintained at the boiling point. Boiling stones were used to prevent boil over. The samples dissolved at $30^{\circ} \mathrm{C}$ and $70^{\circ} \mathrm{C}$ were contained in plastic bottles, which made hot plate evaporation inappropriate. Therefore, water baths (operating at about $85^{\circ} \mathrm{C}$ ) were used to evaporate these solutions. In order to speed up the evaporation process to meet imposing time constraints, some of the samples in plastic bottles were eventually transferred to glass flask. This allowed the samples to be evaporated on a hot plate and significantly improved the rate of evaporation.

After the incremental evaporation of approximately $5-\mathrm{mL}$, the samples were placed in water baths corresponding to the four storage temperatures. Once the samples reached their storage temperature, they were held at temperature for 30-45 minutes (some overnight) and then examined for solids. If no solids were found, the evaporation process continued. If precipitants were observed, the point of precipitation was noted and evaporation continued until there were enough of solids to be analyzed by x-ray diffraction (XRD). This required at least 50mg of dry solids. Once this approximate amount of solids was achieved, the samples were filtered at the appropriate storage temperature.

\subsection{SINGLE AND DOUBLE COMPONENT SOLUBILITY}

To help interpret the results of the multi-component dissolution, single and double component dissolution experiments were conducted. The individual solubility of the following components were tested in $0.1 \mathrm{M}$ $\mathrm{NaOH}$ : sodium nitrite $\left(\mathrm{NaNO}_{2}\right)$, sodium carbonate $\left(\mathrm{Na}_{2} \mathrm{CO}_{3}\right)$, sodium nitrate $\left(\mathrm{NaNO}_{3}\right)$, sodium oxalate $\left(\mathrm{Na}_{2} \mathrm{C}_{2} \mathrm{O}_{4}\right)$, and sodium perrhenate $\left(\mathrm{NaReO}_{4}\right)$. This test also evaluated the solubility of the following chemical combinations: $\mathrm{NaNO}_{3}-\mathrm{Na}_{2} \mathrm{CO}_{3}$ and $\mathrm{Na}_{2} \mathrm{C}_{2} \mathrm{O}_{4}-\mathrm{Na}_{2} \mathrm{CO}_{3}$. The table below shows the approximate amount of each component.

Table 3-2. Single and Double Component Solubility Matrix

\begin{tabular}{|c|c|c|c|c|}
\hline Sample & Component \# & Mass \#1 (g) & Component \#2 & Mass \#2 (g) \\
\hline 1 & $\mathrm{NaNO}_{2}$ & 25.0 & N/A & ---- \\
\hline 2 & $\mathrm{Na}_{2} \mathrm{CO}_{3}$ & 25.0 & N/A & ---- \\
\hline 3 & $\mathrm{NaNO}_{3}$ & 25.0 & N/A & ---- \\
\hline 4 & $\mathrm{Na}_{2} \mathrm{C}_{2} \mathrm{O}_{4}$ & 1.0 & N/A & ---- \\
\hline 5 & $\mathrm{NaNO}_{3}$ & 5.0 & $\mathrm{Na}_{2} \mathrm{CO}_{3}$ & 20.0 \\
\hline 6 & $\mathrm{NaNO}_{3}$ & 12.5 & $\mathrm{Na}_{2} \mathrm{CO}_{3}$ & 12.5 \\
\hline 7 & $\mathrm{NaNO}_{3}$ & 20.0 & $\mathrm{Na}_{2} \mathrm{CO}_{3}$ & 5.0 \\
\hline 8 & $\mathrm{Na}_{2} \mathrm{CO}_{3}$ & 24.0 & $\mathrm{Na}_{2} \mathrm{C}_{2} \mathrm{O}_{4}$ & 1.0 \\
\hline 9 & $\mathrm{Na}_{2} \mathrm{CO}_{3}$ & 24.5 & $\mathrm{Na}_{2} \mathrm{C}_{2} \mathrm{O}_{4}$ & 0.5 \\
\hline 10 & $\mathrm{Na}_{2} \mathrm{CO}_{3}$ & 24.75 & $\mathrm{Na}_{2} \mathrm{C}_{2} \mathrm{O}_{4}$ & 0.25 \\
\hline 11 & $\mathrm{NaReO}_{4}$ & 1.0 & $\mathrm{~N} / \mathrm{A}$ & ---- \\
\hline
\end{tabular}

The single- and double component solutions were dissolved by incrementally adding $0.1 \mathrm{M}$ sodium hydroxide $(\mathrm{NaOH})$. The amount of $0.1 \mathrm{M} \mathrm{NaOH}$ needed to dissolve each sample was recorded along with the weight, $\mathrm{pH}$, and volume of the final solution. This data was compared against the data collected for the multi-component dissolution. 
SRT-RPP-2003-00063

\subsection{DISCUSSION AND RESULTS}

\subsection{SINGLE AND DOUBLE COMPONENT SOLUBILITY}

The trends noticed during this portion of experimentation were close to what was expected. The primary purpose of this test was to explore the effects of the double components on solubility. This understanding would give an idea of how each of the components effects the solubility of the simulant as a whole.

\subsubsection{Single Component Behavior}

It was expected that sodium oxalate would be the least soluble of all components. It was found to be sparingly soluble, with temperature having little effect on the solubility of this compound.

Sodium perrhenate was the most soluble of all components, with temperature having a relatively large effect on its solubility. This was especially evident between $30^{\circ} \mathrm{C}$ and $45^{\circ} \mathrm{C}$.

Sodium nitrate and sodium nitrite exhibited comparable solubility as a function of temperature, with sodium nitrate being slightly more soluble.

With the exception of sodium oxalate, carbonate was not as soluble as the other components. Although the effect of temperature on the solubility was small, it was slightly more soluble at $20^{\circ} \mathrm{C}$ than the other temperatures, and beginning at $30^{\circ} \mathrm{C}$, the solubility increased with increasing temperature. This difference in solubility as a function of temperature provides evidence that elevated temperature is needed to cause the formation of the monohydrate, since the monohydrate is more soluble than the decahrate form. After the monohydrate is formed, there is an increase in solubility.

\subsubsection{Double Component Behavior}

Sodium oxalate has strong effect on the solubility of the two -component system. As the amount of sodium oxalate included in the mixture is decreased, the solubility of the overall matrix increases because oxalate limits the overall matrix solubility. Temperature had a slightly greater effect on the solubility of the combined components than exhibited by the individual components. This is most evident at $70^{\circ} \mathrm{C}$.

The combination of sodium carbonate and sodium nitrate does not behave linearly. It would seem that $80 \%$ carbonate sample would be the most soluble since it contains a larger percentage of the most soluble of the two components, sodium nitrate. However, it is the sample that contains an even amount of the components that is slightly more soluble. This could be related to inaccuracy in the experimental method. Due to time constraints these test were performed more hurriedly than the multi-component tests of Sections 4.2 and 4.3. Therefore, the results may not be as accurate as desired, but they provide valuable insight. 
WSRC-TR-2003-00148, Rev. 0

SRT-RPP-2003-00063

Figure 4-1. Technetium Eluate Single and Double Component Solubility

Tc Eluate Component Solubility

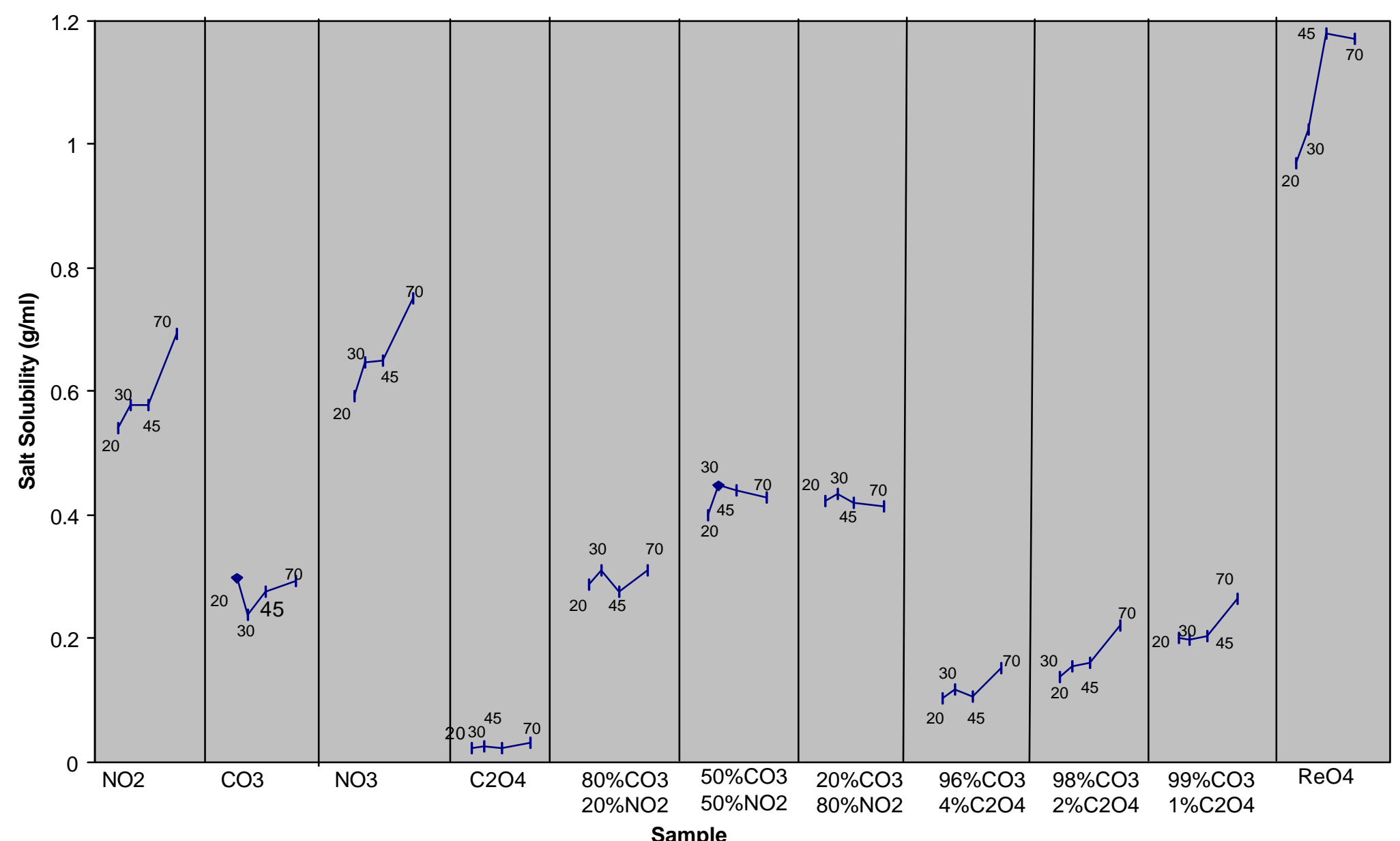


SRT-RPP-2003-00063

\subsection{DISSOLUTION BEHAVIOR}

According to estimates based on the model output, the samples were expected to dissolve at the addition of $60 \mathrm{~mL}$ of water. However, reaching complete dissolution usually required considerably more water. This was especially true for the samples at the $30^{\circ} \mathrm{C}$ storage temperature. These samples contained more dry solids the any other matrix of samples; therefore they required more water to reach dissolution. The samples in the matrix at the $70^{\circ} \mathrm{C}$ storage temperature dissolved closer to the target of $60 \mathrm{~mL}$ of water, relative to the other samples. This is due to higher solubility at elevated temperatures. The samples in the $70^{\circ} \mathrm{C}$ matrix contained approximately the same concentration of solids as the other matrixes, excluding the samples within the $30^{\circ} \mathrm{C}$ matrix.

There were instances where complete dissolution was not obtained. After the addition of relatively large amounts of water, a very fine amount of solids remained in the container. This occurred in samples 8 and 9 of the $20^{\circ} \mathrm{C}$ matrix as well as in other samples of other matrixes. Samples $8 \& 9$ were filtered and the solids were submitted for XRD analysis. The physical appearances of these samples were representative of the types of remaining solids in other samples as well $(1,3,18)$. XRD analyses revealed that both samples contained aluminum hydroxide $\mathrm{Al}(\mathrm{OH})_{3}$ as the remaining solid.

Several samples were withdrawn from the matrix because of an inordinate amount of indissolubility. Samples 7, 10, 12 and 15 were removed from all matrixes, excluding the matrix at $45^{\circ} \mathrm{C}$. Within the $45^{\circ} \mathrm{C}$ matrix, samples $1,4,7$, and 13 were withdrawn.

The majority of the samples at 30 and $45^{\circ} \mathrm{C}$ contained solids that did not dissolve completely. Although these solids were not submitted for XRD analyses, they had to be removed by filtration before the evaporation process could begin in order to see the onset of precipitation. The matrix at $20^{\circ} \mathrm{C}$ had relatively few remaining solids when compared to the aforementioned matrixes. The matrix at $70^{\circ} \mathrm{C}$ contained no samples where remaining solids could be identified. Once again this is likely attributed to the higher temperature of this matrix.

Due to the absence atmospheric boiling conditions, there was little or no formation of $\mathrm{Na}_{2} \mathrm{CO}_{3}-\mathrm{H}_{2} \mathrm{O}$, the monohydrate form of sodium carbonate in the 30 and $45^{\circ} \mathrm{C}$ samples. As will be mentioned later, the monohydrate is the expected form of $\mathrm{Na} 2 \mathrm{CO} 3$, and the solubility of the monohydrate is greater than that of the decahydrate $\left(\mathrm{Na}_{2} \mathrm{CO}_{3}-10 \mathrm{H}_{2} \mathrm{O}\right)$, especially near $30^{\circ} \mathrm{C}$.

The observed solubility levels (in total grams of solid per liter) after complete dissolution are plotted in Figure 4-3. The calculated solubility values are listed in Table 4-1. Generally, the dissolution curves in Figure 4-3 exhibit a behavior of increased solubility with increasing temperature. The dissolution portion of the chart follows typical dissolution behavior, except for simulant numbers 2,3 and 18 . For simulants 2 , 3 and 18 , the salt concentration $(\mathrm{g} / \mathrm{mL})$ for dissolution at the $20^{\circ} \mathrm{C}$ storage temperature is approximately equal to the salt concentration at the $70^{\circ} \mathrm{C}$ storage temperature. This causes the dissolution curves to have a unique $\mathrm{V}$-shape, indicating that these simulants are relatively soluble at $20^{\circ} \mathrm{C}$. Initially, solubility decreases as the temperature increases. However, the solubility begins to increase at $30^{\circ} \mathrm{C}$ and $45^{\circ} \mathrm{C}$. Simulants 2, 3 and 18 share a common trait in composition. The compositions of each contain more sodium nitrate than sodium carbonate.

Of the six samples that contain sodium oxalate $(3,5,6,8,13$, and 17$)$, all exhibit a similar slope as the solubility increases as a function of temperature. This especially holds true for samples 4,5 , and 13 . Samples 6,8 , and 17 have outlying points at 20,70 , and $30^{\circ} \mathrm{C}$ respectively, but the slope is relatively similar for all samples containing oxalate.

Consistent dissolution behavior is also exhibited in the samples that do not contain oxalate. This is evident in samples 9,11, and 16. The dissolution curves for these three samples are in good agreement with each 
SRT-RPP-2003-00063

other. This is as expected because the composition of these samples are similar. The composition of each is dominated by carbonate, which composes $69.7,69.1$ and $71.0 \%$ of the simulants composition respectively.

Additionally, there is excellent agreement, between the model's predicted solubility and the solubility values obtained through experimentation at the $70^{\circ} \mathrm{C}$ matrix. This is true for any simulant that does not contain sodium oxalate, which are simulants \# 1, 2, 3, 9, 11, 14, and 16. For simulants that contain sodium oxalate, the model consistently predicts a solubility that is higher than what is observed through dissolution.

\subsection{EVAPORATION BEHAVIOR}

The solids were filtered from the solution at the storage temperature. These solids were then allowed to cool to ambient temperature before being submitted for analysis. The heating of the sample would cause the formation of the monohydrate form of sodium carbonate. As the samples cooled the expectation would be for the monohydrate to revert back to the decahydrate. However, this was not observed because the solids were removed from solution before the cooling began. For the decayhdrate to form an excess of water must be present. This would explain why XRD analysis did not yield decahydrate as a precipitant as predicted by the model (See Table 4-2).

The simulants differed in their behavior during evaporation. In some simulants the solids would form slowly as water was being evaporated from the system. In other samples the solids would appear suddenly in large quantities. Also there were instances where the solids were present at the high temperatures of evaporation, but when the samples were cooled to their storage temperature, the solids would dissolve. The pictures below demonstrate this effect.

Figure 4-2. Formation and Dissolution of Sodium Carbonate Monohydrate
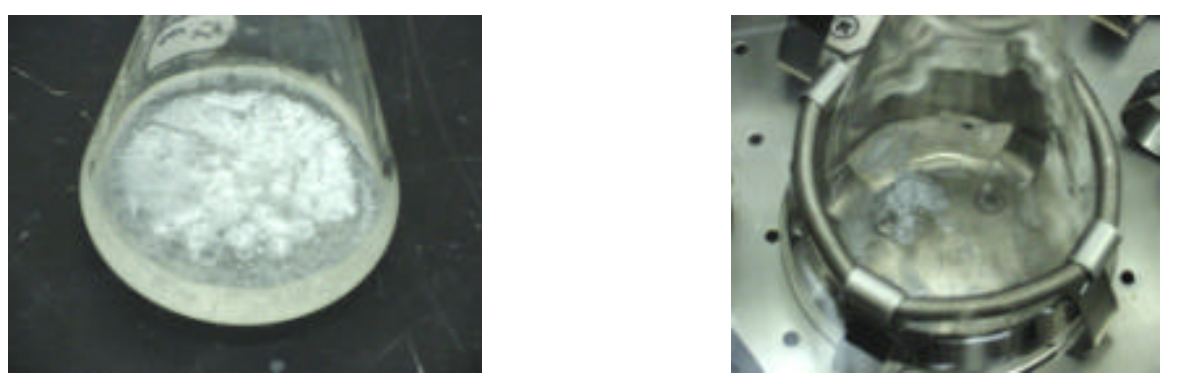

The picture to the on the left shows simulant solids that formed during evaporation at temperatures exceeding $100^{\circ} \mathrm{C}$. The picture on the right shows the same solid cooling in the bath at $30^{\circ} \mathrm{C}$ and beginning to break up and dissolve.

Figure 4-3 also contains the calculated solubility levels following evaporation to the initiation of precipitation. The calculated solubility values are listed in Table 4-1. Figure 4-3 provides a comparison of the solubility curves for dissolution and evaporation of the Tc eluate simulants. There is a sharp increase in solubility that occurs at the $30^{\circ} \mathrm{C}$ holding temperature during evaporation. This increase may be attributed to a transition between the decahydrate to the monohydrate form of sodium carbonate. As described in the Merck Index, this transition occurs between $32^{\circ} \mathrm{C}$ and $35^{\circ} \mathrm{C} .^{2}$

In most instances the curves behave similarly, with the evaporation solubility being higher than the dissolution. This primary difference between the two curves may also be attributable to the formation of the

\footnotetext{
${ }^{2}$ Susan Burdovari ed., The Merck Index, $11^{\text {th }}$ ed., Merck \& Co. Inc., Rahway, N.J., 1989.
} 
SRT-RPP-2003-00063

more soluble monohydrated sodium carbonate, while at the evaporation temperature, which does not convert back to decahydrate.

The spike in solubility $(\mathrm{g} / \mathrm{mL})$ at $30^{\circ} \mathrm{C}$ is more pronounced in the evaporation curve for the following samples: $1,2,3,9,11,16$, and 18 . This is not surprising, since these samples are also void of sodium oxalate. Individually, sodium oxalate is the least soluble component of the Tc eluate simulations. The samples that contain sodium oxalate still exhibit the spike at $30^{\circ} \mathrm{C}$, yet it is subdued in comparison. The data clearly points to the formation of the monohydrated sodium carbonate, which has a much higher solubility in the $32-35^{\circ} \mathrm{C}$ range. The solubility of the simulants during evaporation that do not contain sodium oxalate, range from $0.39 \mathrm{~g} / \mathrm{mL}$ to $1.25 \mathrm{~g} / \mathrm{mL}$. The solubility of the simulants during evaporation that contain sodium oxalate have a much narrower range of, range from $0.25 \mathrm{~g} / \mathrm{mL}$ to $0.44 \mathrm{~g} / \mathrm{mL}$

Due to the spike in solubility at $30^{\circ}$, it is difficult to relate any solubility behavior as a function of temperature between the dissolution curve and the evaporation curve near $30^{\circ} \mathrm{C}$. The sudden increase in solubility that is present in every sample at the $30^{\circ} \mathrm{C}$ storage temperature in the evaporation curves is not present in the dissolution curves. Similarly, the gradual slopes that are exhibited within the dissolution curves that contain oxalate are not exhibited in the evaporation curves.

The spike at $30^{\circ} \mathrm{C}$ in the simulations maybe attributed to the transition between the decahydrate and the monohydrate form of sodium carbonate. As stated earlier, this transition occurs at approximately $32^{\circ} \mathrm{C}$. This spike is only seen during the evaporation portion of experimentation. During dissolution, the temperature never crosses the $32^{\circ} \mathrm{C}$ threshold significantly. Similarly, the solubility during the single- and double-component dissolution tests (Section 4.1), the samples containing sodium carbonate did not demonstrate solubility behavior that is indicative of monohydrate. Therefore, it is unlikely that the monohydrate of sodium carbonate was formed. Conversely, during the evaporation process the simulants stored at this storage temperature were heated to their boiling point and cooled again to $30^{\circ} \mathrm{C}$ for storage. This repeated heating provided the energy needed to form the monohydrate. Therefore, the solubility curve increases substantially near $30^{\circ} \mathrm{C}$.

The solubility spike cause by the transition from the decahydrate to monohydrate form of sodium carbonate during evaporation and the lack of this transitional spike during dissolution, distorts the relationship between the dissolution and evaporation trends. With the removal of the $30^{\circ} \mathrm{C}$ data from the evaporation and dissolution curves, there is consistent agreement in the shape of the dissolution and evaporation curves at all storage temperatures.

After the evaporation data was recorded, density measurements were done to verify the evaporation results. Once the solids where removed from the simulants for XRD analysis, as described above, the remaining liquid was analyzed for density using an Anton Paar DMA 4500. Density measurement where taken at $20^{\circ} \mathrm{C}$ and $50^{\circ} \mathrm{C}$ for each sample regardless of storage temperature (see attachment 1). Figure 4-4 shows the relationship of the density measured at $50^{\circ} \mathrm{C}$ for each simulant and the evaporation trends. The relative trends between the two curves are in good agreement. This provides evidence that the evaporation experiments are accurate. Furthermore, if post-precipitation had not occurred there may have been more agreement between the density and evaporation results. 
WSRC-TR-2003-00148, Rev. 0

SRT-RPP-2003-00063

Figure 4-3. Technetium Eluate Solubility Data

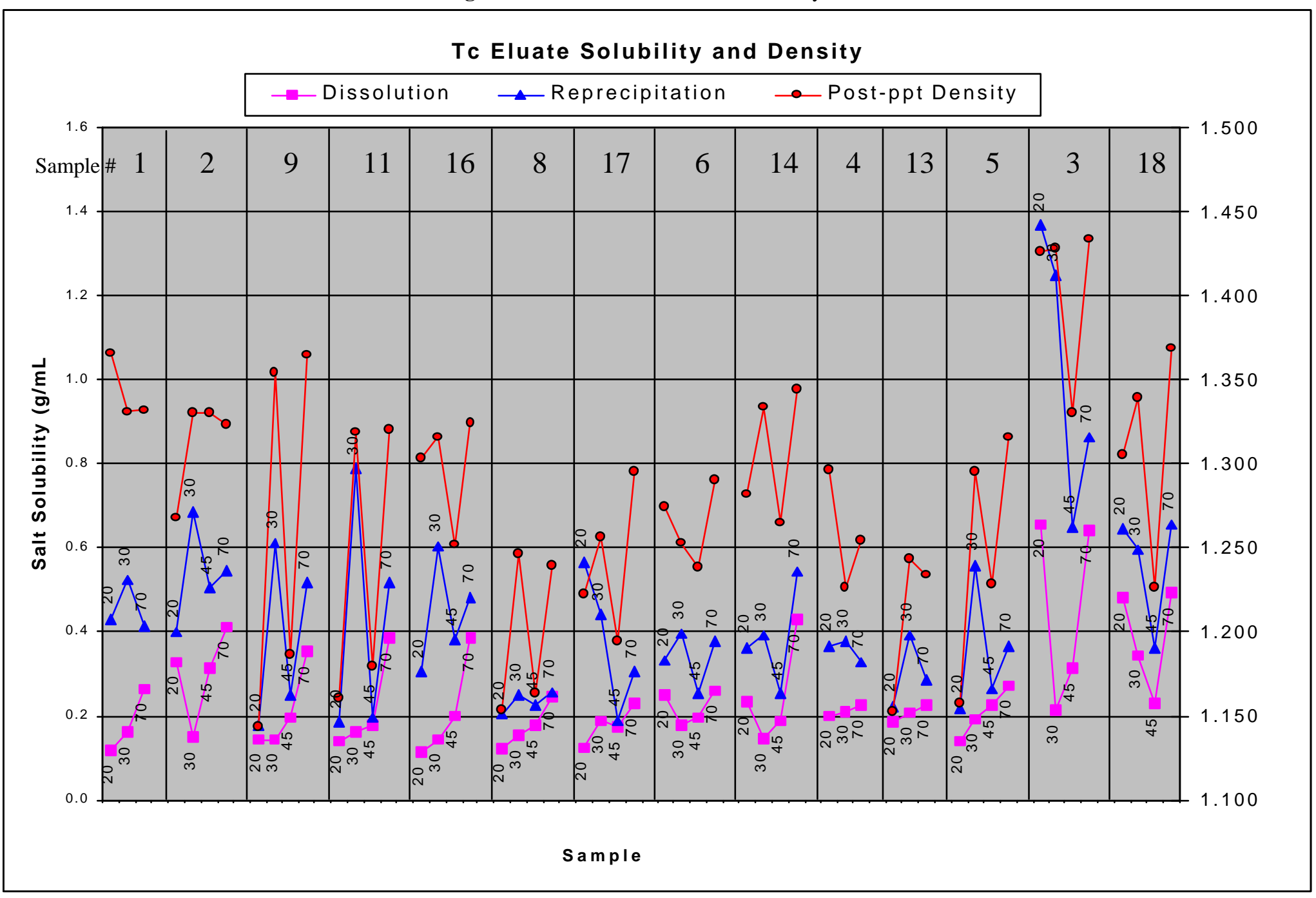


SRT-RPP-2003-00063

\subsection{PRECIPITATION DATA}

The precipitants yielded during evaporation were characterized by $\mathrm{x}$-ray diffraction (XRD). Adequate quantitative analysis could not be obtained. A qualitative presentation of the precipitation data is shown in table 4-1. Table 4-1 indicates the major, moderate, and minor precipitants for each test. The major precipitants are indicated with four large X's. The increasingly smaller precipitants are indicated by three large X's and two small x's.

Also included in Table 4-1 are the calculated solubility values. The concentrations are calculated for the dissolution and precipitation portions of experimentation. Dissolution represents the solubility when dissolution of solids was complete. Precipitation represents the solubility when solids are first observed in solution. These can be compared against the concentrations obtained by the model $(\mathrm{g} / \mathrm{mL})$ on the far right of the table. Also the table below contains the calculated solubility at the point when there were enough solids to be filtered (filter $\mathrm{g} / \mathrm{mL}$ ). In some cases, the precipitation and filtering points occurred at the same time. 
WSRC-TR-2003-00148, Rev. 0

SRT-RPP-2003-00063

Table 4-1. Experimental Precipitation and Solubility

\begin{tabular}{|c|c|c|c|c|c|c|c|c|c|c|c|c|}
\hline Simulant \# & Temp C & & & & & & & & \multicolumn{4}{|c|}{$\begin{array}{l}\text { Salt Concentrations } \\
\end{array}$} \\
\hline & & Na2CO3-H2O & $\frac{\mathrm{NaNO}^{2}}{\mathrm{x} x}$ & $\frac{\mathrm{NaNO2}}{X X X}$ & KReO4 & $\mathrm{Na}_{2} \mathrm{C} 204$ & $\mathrm{Al}_{\mathrm{HOH}} 3_{3}$ & 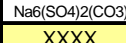 & $\frac{\text { diss. }(\mathrm{g} / \mathrm{mL})}{0.17}$ & $\frac{\mathrm{evap}(\mathrm{g} / \mathrm{mL}}{0,430}$ & filiter (g/mL & model $(\mathrm{g} / \mathrm{mL})$ \\
\hline$\frac{1}{1}$ & $\frac{20}{30}$ & & $\frac{x x}{x x}$ & & & & & $\frac{x \times x x}{x x x x}$ & $\frac{0.117}{0.163}$ & 0.4506 & 0.155 & $\begin{array}{l}1.081 \\
0.536\end{array}$ \\
\hline 1 & 45 & & & & & & & & & & & \\
\hline 1 & 70 & $\overline{x x}$ & & $x x$ & & & & $x x x x$ & 0.266 & 0.414 & 0.542 & 0.424 \\
\hline & 20 & & $x x$ & $x x x x$ & $x x x x$ & & & $x x x$ & 0.329 & 0.401 & 0.428 & 0.624 \\
\hline & 30 & & & & $\frac{x x}{x x}$ & & & $\frac{x x x x}{x y x}$ & 0.150 & 0.687 & 0.687 & 0.514 \\
\hline & 45 & & & $x x$ & $x x$ & & & $x x x x$ & 0.312 & 0.507 & 0.672 & \\
\hline 2 & 70 & & & $x x$ & $x x$ & & & $x x x x$ & 0.413 & 0.546 & 0.546 & 0.423 \\
\hline 9 & 20 & XXXX & & & & & & $x X X X$ & 0.143 & 0.175 & 0.175 & 0.276 \\
\hline 9 & 30 & $x x$ & & & & & & $x x x x$ & 0.142 & 0.610 & 0.610 & 0.521 \\
\hline 9 & 45 & $x x x x$ & & & & & & $x x x x$ & 0.196 & 0.251 & 0.251 & 0.472 \\
\hline 9 & 70 & $x x$ & & $x x$ & & & & $x \mathrm{xxx}$ & 0.354 & 0.518 & 0.518 & 0.400 \\
\hline 11 & 20 & $X X X X$ & $x x$ & & & & & & 0.138 & 0.186 & 0.186 & 0.225 \\
\hline & 30 & $x x x x$ & $x x$ & $x x$ & & & & $x x$ & 0.164 & 0.790 & 0.790 & 0.430 \\
\hline 11 & 45 & $x x x x$ & $\frac{n x}{x x}$ & & & & & & 0.178 & 0.1966 & 0.231 & 0.438 \\
\hline 11 & 70 & $x x x x$ & $x x$ & & & & & & 0.384 & 0.516 & 0.516 & 0.400 \\
\hline 16 & 20 & $x x x x$ & $x x$ & & & & & & $\begin{array}{ll}0.114 \\
\end{array}$ & 0.306 & 0.382 & 0.215 \\
\hline 16 & 30 & $x x x x$ & $x x$ & & & & & & 0.144 & 0.604 & 0.604 & 0.403 \\
\hline & & $x x x x$ & & & & & & & 0.201 & 0.381 & 0.428 & 0.417 \\
\hline 16 & 70 & $x x x x$ & & & & & & & 0.387 & 0.484 & 0.484 & 0.386 \\
\hline 8 & 20 & $x X X X$ & & & & & & & 0.122 & 0.204 & 0.237 & 0.225 \\
\hline & 30 & & & & & $x x x x$ & & & 0.153 & 0.248 & 0.359 & 0.420 \\
\hline 8 & 45 & $x x x x$ & & & & & & & 0.177 & 0.225 & 0.225 & 0.439 \\
\hline 8 & 70 & & & & & $x x x x$ & & & 0.244 & 0.257 & 0.295 & 0.402 \\
\hline 17 & 20 & $x x x x$ & & & $x x$ & & & & 0.125 & 0.565 & 0.565 & 0.237 \\
\hline 17 & 30 & $\mathrm{xx}$ & & & $x x$ & 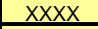 & & & 0.188 & 0.443 & 0.443 & 0.620 \\
\hline$\frac{17}{17}$ & 45 & $x x x x$ & $x x$ & & & & & & 0.175 & 0.190 & 0.265 & 0.448 \\
\hline 17 & 70 & $x x$ & $x x$ & & $x x$ & $x x x x$ & & & 0.230 & 0.306 & 0.415 & 0.412 \\
\hline 6 & 20 & $x \mathrm{XXX}$ & & & $x x$ & & & $\overline{x x}$ & 0.250 & 0.332 & 0.544 & 0.263 \\
\hline 6 & 30 & & $x x$ & & $x x$ & XXXX & & & 0.176 & 0.396 & 0.396 & 0.640 \\
\hline 6 & 45 & $x x x x$ & $x x$ & & $x x$ & & & & 0.197 & 0.254 & 0.375 & \\
\hline 6 & 70 & & & $x x$ & $x x$ & $x x x x$ & & & 0.261 & 0.379 & 0.392 & 0.428 \\
\hline 14 & 20 & $x x x x$ & $x x$ & & $x x$ & & & & 0.234 & 0.362 & 0.494 & 0.270 \\
\hline 14 & 30 & $\mathrm{xxXX}$ & $x x$ & $x x$ & $x x x x$ & & & & 0.148 & 0.394 & 0.394 & 0.650 \\
\hline 14 & 45 & XXXX & $x x$ & & $x x$ & & & & 0.190 & 0.253 & 0.414 & 0.463 \\
\hline 14 & 70 & $x x$ & & & $x X X X$ & & & & 0.428 & 0.543 & 0.543 & 0.430 \\
\hline 4 & 20 & $x x$ & $x \mathrm{xxX}$ & & & $x \mathrm{xxx}$ & & & 0.199 & 0.366 & 0.636 & 0.830 \\
\hline 4 & 30 & & $x x$ & & & $\mathrm{XXXX}$ & & & 0.210 & 0.376 & 0.413 & 0.863 \\
\hline$\frac{4}{4}$ & $\frac{45}{70}$ & & & & & $x X X X$ & & & 0.227 & 0,328 & 0.387 & $\frac{0.512}{0.47}$ \\
\hline & & & & & & & & & & & & \\
\hline$\frac{13}{13}$ & 20 & $x x$ & $x x$ & & & & $\frac{x x x}{x y y z}$ & & 0.185 & 0.222 & 0.222 & 0.290 \\
\hline 13 & $\frac{30}{45}$ & & & & & & & & & & & 0.989 \\
\hline 13 & 70 & & & & & $\mathrm{XXXX}$ & $x x$ & & 0.226 & 0.285 & 0.330 & $\frac{0.455}{0.455}$ \\
\hline & 20 & $y$ & & & & & YYYYY & & 0129 & 0218 & 0218 & 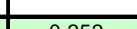 \\
\hline 5 & 20 & $\frac{2 \pi}{x x}$ & $\frac{2 x}{x x}$ & & $x x x x$ & $x x$ & $x \times x x$ & & 0.139 & $\begin{array}{l}0.218 \\
0.557\end{array}$ & $\begin{array}{l}0.218 \\
0.557\end{array}$ & $\frac{0.252}{0.640}$ \\
\hline 5 & 45 & $\frac{X X X X}{X X X}$ & $\frac{x X X}{x X X}$ & & $\frac{x x x}{x x y}$ & & & & 0.925 & 0266 & 0341 & $\frac{0.460}{0462}$ \\
\hline 5 & 70 & $x x$ & & & & $X X X X$ & & & 0.271 & 0.365 & 0.412 & $\frac{0.424}{0.424}$ \\
\hline 3 & 20 & & YYYYY & & YYYYY & & & & 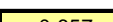 & 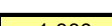 & 70 & 8770 \\
\hline 3 & 30 & $x x x$ & 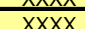 & & $\frac{\lambda \sqrt{n x}}{x x}$ & & & & 0.014 & 1.248 & 1248 & $\frac{0.152}{0.796}$ \\
\hline 3 & 45 & $\frac{\pi x}{x x}$ & $\frac{x \times x y}{x y X x}$ & & $\frac{\pi}{x y}$ & & & & 0315 & 0650 & 0650 & 0.76 \\
\hline 3 & 70 & $\overline{X X X X}$ & $x X X X$ & & $\frac{x x}{x x}$ & & & & 0.642 & 0.863 & 0.863 & 0.661 \\
\hline & & & & & & & & & & & & \\
\hline 18 & 20 & $x x$ & $x x x x$ & $x x$ & & & & & 0.485 & 0.646 & 0.646 & 0.823 \\
\hline & 30 & $x$ & $x x$ & & & & & & 0.342 & 0.597 & 0.597 & 0.839 \\
\hline & 70 & $\frac{A \wedge A \wedge}{X X X X}$ & $\frac{2 \pi n x}{x x}$ & & & & & & 0.230 & 0.004 & 0.3645 & 0.527 \\
\hline 18 & 10 & $x x x x$ & & & & & & & 0.496 & 0.655 & & 0.491 \\
\hline
\end{tabular}


SRT-RPP-2003-00063

\subsubsection{Precipitating Species}

$\underline{\text { Sodium Carbonate }}$

Sodium carbonate is a major precipitant in every matrix. This is not surprising since sodium carbonate is the most dominant chemical component in many of the matrices. Only in the instances where sodium carbonate consists of less than $50 \%$ of the chemical composition is it not found as a precipitant. This occurs in samples 1, 2, 4, and 13, where sodium carbonate is $27.3 \%, 14.7 \%, 35.4 \%$, and $48.5 \%$ respectively, of the total. However, there are a few cases where sodium carbonate is less than $50 \%$ and is a major precipitant. This is exhibited in simulants this 3,14 , and 18 where simulants consist of $16.2 \%$, $48.2 \%$, and $18.6 \%$ respectively. ${ }^{3}$

$\underline{\text { Sodium Oxalate }}$

Sodium oxalate is not included as a chemical component in all of the technetium eluate simulants. It is only included in simulations $4,5,6,8,13,14$, and 17 . Furthermore, in these simulants it is less than $1.5 \%$ of the chemical composition. However, sodium oxalate is a prevalent precipitant. These results are not surprising due to the fact that sodium oxalate is the least soluble of all the chemical components. This was demonstrated by the individual chemical solubility test. See Figure 4-1.

Of the samples that contain sodium oxalate, all precipitate oxalate at $70^{\circ} \mathrm{C}$. Samples $4,6,8$, and 17 precipitate oxalate at the $30^{\circ} \mathrm{C}$ holding temperature as well. Sample 4 precipitated sodium oxalate at $20^{\circ} \mathrm{C}$ and $45^{\circ} \mathrm{C}$ in addition to the aforementioned holding temperatures. The presence of sodium oxalate dictates the precipitants that occur during evaporation. Every simulant that contains sodium oxalate precipitates it at one or more of the storage temperatures. The simulants that do not contain sodium oxalate precipitate either carbonate or burkeite $\left(\mathrm{Na}_{6}\left(\mathrm{CO}_{3}\right)\left(\mathrm{SO}_{4}\right)_{2}\right)$. Burkeite only occurs as a precipitant in simulations 1,2 , and 9. Simulation 9 also has carbonate as a precipitant in addition to burkeite. As will be discussed later, burkeite only precipitates when the concentration sodium sulfate is relatively high. When sodium carbonate is high relative to sodium sulfate, there will be competition between sodium carbonate and burkeite for precipitation.

\section{Potassium Perrhenate}

Potassium perrhenate $\mathrm{KReO} 4$ serves as a non-radiological replacement for potassium pertechnitate $\left(\mathrm{KTcO}_{4}\right)$. Detecting the existence of sodium perrhenate could not be performed using XRD analysis because the peaks for sodium carbonate and those for sodium perrhanate are almost identical. Therefore, the higher the sodium carbonate concentration the more difficult it is to detect sodium perrhanate.

Excluding the hydroxide salts, every component of the simulant precipitates in some form. However, it is surprising to have potassium perrhenate be a major precipitate from samples 2,3,5, and 17 since potassium perrhenate makes up less than $1 \%$ of any of the simulants. Furthermore it is the most soluble individual component according to the single - dual solubility test. See Figure 4-1. However, the precipitation of perrhenate is generally consistent with modeling expectations, as will be discussed in subsequent sections.

\section{Burkeite}

Burkeite $\left(\mathrm{Na}_{6} \mathrm{CO}_{3}\left(\mathrm{SO}_{4}\right)_{2}\right)$ is a rare mineral. It is described as a white, grayish, sulfatocarbonate of sodium. ${ }^{3}$ Although it is not a chemical component used to form the technetium simulant, it is formed with in the simulant by an interaction between sodium sulfate and sodium carbonate. Burkeite is a major precipitant for every matrix for simulants 1,2, and 9. According to the precipitation data, burkeite is formed whenever sodium sulfate is greater than $10 \%$ of the chemical components. It is unknown what effect a sulfate concentration between 1.0 and $10.0 \%$ might exhibit.

\footnotetext{
${ }^{3}$ P. Thrash ed., A Dictionary of Mining Minerals and Related Terms, U.S. Dept. of Interior, Bureau of Mines. 1968.
} 
SRT-RPP-2003-00063

\section{Sodium Nitrate}

According to the evaporation results, sodium nitrate precipitates whenever it composes a large portion of the chemical components. Whenever the simulant contained greater than $38 \%$ sodium nitrate, it became a precipitant of significant quantities during evaporation test. This occurred in samples $3,4, \& 18$ where the simulants contained $70 \%, 42.7 \%$, and $38.2 \%$ of sodium nitrate respectively.

\section{$\underline{\text { Sodium Nitrite }}$}

Analysis of the filtered simulants revealed sodium nitrite as a solid at $20^{\circ} \mathrm{C}$ whenever there is an abundant amount with in the simulant. This behavior is exhibited in simulations 1 and 2 , both of which contain more than $40 \%$ sodium nitrite. The sodium nitrite is more prevalent as a precipitant at the $20^{\circ} \mathrm{C}$ storage temperature than at any other temperature because of its relatively high solubility at elevated temperatures. The individual solubility of sodium nitrite is demonstrated in Figure 4-1.

\subsubsection{Post-Precipitation}

In some cases, upon filtering the precipitants from the simulant solution, additional precipitants would form over night in some instances. Using x-ray diffraction analysis, it was discovered that these postprecipitants were the monohydrated form of sodium carbonate. The OLI evaporation model predicts that decahydrated sodium carbonate precipitates below $32^{\circ} \mathrm{C}$. The Merck Index describes the decahydrated from of sodium carbonate as transparent crystals that readily effloresces on exposure to air into the monohydrated form. ${ }^{2}$ The monohydrated form is stable in air up to $50^{\circ} \mathrm{C}$ and becomes anhydrous over $100^{\circ} \mathrm{C}$. Therefore, using X-ray diffraction to characterize the post-precipitant would yield the monohydrate regardless of the initial form of the post-precipitant. As predicted, X-ray diffraction showed the monohydrate as the precipitant. However, we are unable to validate the decahydrate as the initial form.

Post-precipitation was evident in many of the simulations. Although post-precipitants occurred within every matrix of samples, many occurred at temperatures below the storage temperature. Post-precipitation usually occurred after filtration while the sample was allowed to cool to room temperature. The possibility of post-precipitation occurring while the solution was at storage temperature for an extended period of time (other than those at $20^{\circ} \mathrm{C}$ ) was never tested. However, there is reason for concern because of postprecipitation of samples with in the $20^{\circ} \mathrm{C}$ storage temperature matrix, since there is no relative difference between room temperature and this storage temperature.

The following pictures show the post-precipitant formed during the filtration of Tc eluate simulant number 16 at the $20^{\circ} \mathrm{Cmatrix}$. The beaker to the left shows the presumed decahydrated form of sodium carbonate. The beaker to the right shows a portion of the post-precipitant that has been exposed to air for greater than $24 \mathrm{hrs}$. In appearance it closely matches the description given by the Merck Index for the monohydrated form of sodium carbonate.

Figure 4-4. Sodium Carbonate Solids

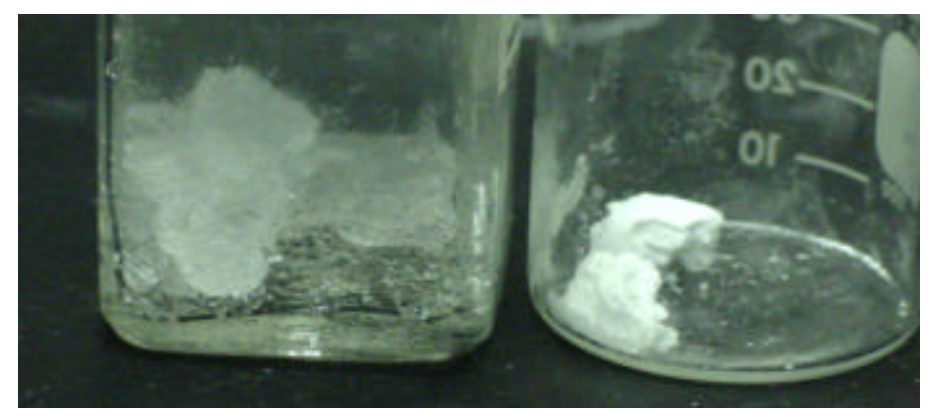


SRT-RPP-2003-00063

\subsection{EXPERIMENTAL DATA VS. MODELING PREDICTIONS}

Figure 4-4 and Table 4-2 provide an overview comparison of modeling predictions with experimental observations. Figure 4-4 depicts the results from experimentation and modeling. The upper portion of the chart gives the sample number and, the major precipitant at each holding temperature. Directly below the precipitant data is the mole percent for each component. Finally the bottom portion of the chart provides three curves. The blue curve is the solubility in grams per liter at the precipitation point during evaporation. The red curve, is the solubility during dissolution. The yellow curve represents the calculated solubility predicted by the computer model. The chart is ordered in a manner so that simulants that exhibit similar behavior are grouped together.

\subsubsection{Solubility}

Within the modeling data the transition between the decahydrate and monohydrate forms of sodium carbohydrate has a large impact on the solubility trends. These forms of carbonate exhibit different solubility trends with respect to temperature. The decahydrate exhibits a normal solubility curve, the gradual increase in solubility coincides with an increase in temperature. The monohydrate yields a trend of reverse solubility from $70^{\circ} \mathrm{C}$ to $30^{\circ} \mathrm{C}$. As mentioned previously the transition between the two forms occurs at approximately $32^{\circ} \mathrm{C}$. Therefore, according to the model, the inflection point in the solubility curve occurs at this temperature. The solubility for most samples increases from $20^{\circ} \mathrm{C}$ to $30^{\circ} \mathrm{C}$. After $30^{\circ} \mathrm{C}$ the samples exhibit reverse solubility and sharply decrease in most instances. This decrease in solubility is continued throughout the remaining storage temperatures, although it is sometimes offset by an increase in solubility of the other components - sodium nitrate, sodium nitrite, potassium perrhenate, sodium oxalate.

The modeling predictions for some samples vary slightly from the description above. Simulants 1, 2, 4, 13, and 18 do not exhibit the steep inflection caused by the transition between the decahydrate and monohydrate form of sodium carbonate. This may be caused by the relatively small amount of sodium carbonate within their composition relative to other compounds. Samples 1 and 2 contain the highest concentrations of sodium nitrite (43.7 and 41.9 respectively). Samples 4, 13, and 18 contain more sodium nitrate than sodium carbonate.

The model prediction for Sample 1 at $20^{\circ} \mathrm{C}$ is questionable. According to modeling data, the solubility of carbonate in simulation 1 at $20^{\circ} \mathrm{C}$ is greater by a factor of two than at $30^{\circ} \mathrm{C}$. The model predicts the ionic strength of the sample to be 29 , and the sodium molarity to be $15.7 \mathrm{M}$. Although these values maybe possible, they are not likely. They are high relative to the other values for sodium molarity and sample ionic strength.

As described earlier, peaks seen at the transition between the monohydrate and decahydrate of sodium carbonate is evident in the model. The evaporation data gathered by experimentation also shows this same pattern. However, they disagree in terms of samples in which this behavior is exhibited. The evaporation data gives pronounced spikes in the absence of oxalate. However, the model yields very pronounced spikes in the presence of oxalate. This is considered to be an over prediction of the solubility by the model. The results of the single and double component solubility experiments show that sodium oxalate is not easily dissolved, nor does its solubility change much as a function of temperature (Figure 4-1). The dissolution and evaporation data also show that simulants that contain oxalate are less soluble.

Other areas of disagreement between the model and evaporation data occur at $45^{\circ} \mathrm{C}$. For all samples, the evaporation curve consistently depicts the $45^{\circ} \mathrm{C}$ solubility lower than the solubility at $30^{\circ} \mathrm{C}$. However, model predictions do not agree with the solubility behavior shown for evaporation. The model consistently overstates the solubility for the samples at $45^{\circ} \mathrm{C}$. For most samples, the model predicts the solubility of the 
$45^{\circ} \mathrm{C}$ samples on par with or above the solubility at $30^{\circ} \mathrm{C}$. This contradiction between the model and the evaporation data is due to a modeling overstatement at the $45^{\circ} \mathrm{C}$ storage temperature.

The solubility for the dissolution data at $20^{\circ} \mathrm{C}$ were relatively low when compared to those predicted by the model and those observed in the evaporation data. This trend is true for most simulants. The energy absorbed from the heating and cooling the samples during evaporation may explain the differences between evaporation and dissolution solubility data with in the $20^{\circ} \mathrm{C}$ matrix. The effects of heating and cooling are also taken in to account within the model. As mentioned earlier, this heating causes the formation of the monohydrate form of sodium carbonate. The dissolution simulants at $20^{\circ} \mathrm{C}$ were not heated, therefore dissolution kinetics are not as favorable. Also, they may contain primarily the decahydrate as the precipitate and a correspondingly lower relative solubility. 
WSRC-TR-2003-00148, Rev. 0

SRT-RPP-2003-00063

Figure 4-5. Technetium Eluate Precipitation and Solubility

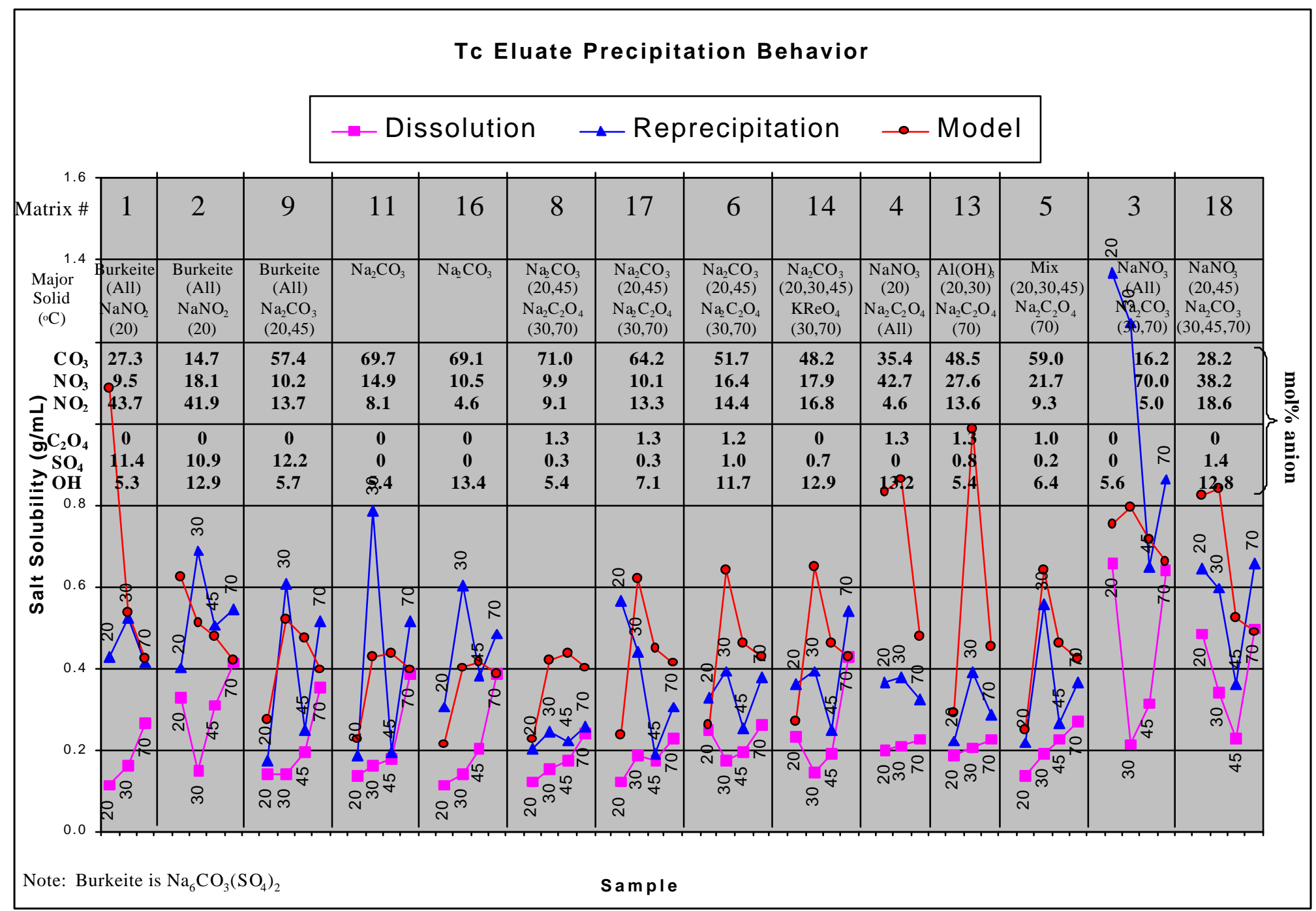


SRT-RPP-2003-00063

\subsubsection{Precipitation}

The chart below shows the predicted precipitants versus those precipitants that were obtained through experimentation. The notations have been arbitrarily assigned. For the solids formed (left half of the table), the "XXXX" and "xx" signify major and minor precipitants, while "XXX" denotes precipitant quantities between the two extremes. For the solids predicted (right side of the table), the "XXXX" denotes an expected solid, "XXX" identifies a solid with reasonable probability of forming, and "xx" denotes a solid with a fair chance of forming. It is important to note that just because a solid is expected to form ("XXXX" on the right side of the table), it does not necessarily follow that it will be a major precipitate. The green shaded boxes are used to notate agreement between the predicted and experimental precipitants. The red shaded boxes are used to signify a disagreement between predicted and observed solids. If a red-shaded box on the right side of the table contains markings that signify that a precipitant was predicted, then it follows that no precipitant was found within that sample at the experimental temperature. 
WSRC-TR-2003-00148, Rev. 0

SRT-RPP-2003-00063

Table 4-2. Experimental Precipitants vs. Modeling Precipitants

\begin{tabular}{|c|c|c|c|c|c|c|c|c|c|c|c|c|c|c|c|c|}
\hline \multirow{2}{*}{ Na20 $03 \cdot$ - 220} & $\frac{\mathrm{SOUN11}}{\mathrm{N}}$ & ORME & URINGE E & PFBIMEN & CATION & & TATE & & 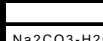 & & SPBEDIC & EDBYC & MPUTER & 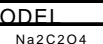 & 年 & Na2504 \\
\hline & $\frac{x x}{x x}$ & $X X X$ & $\mathrm{~N}_{1}$ & Nacucous & Alumis & Tad & $\frac{1}{1}$ & $\frac{20}{20}$ & Nazcosene & 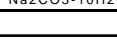 & Navios & XXXX & Nheovis & Nacoves & Allonis & Nacsols \\
\hline$x x$ & & $x x$ & & & & $\frac{X X X X}{X X X X}$ & & $\begin{array}{l}30 \\
70\end{array}$ & & & & & & & & $\overline{x x}$ \\
\hline & $x x$ & & $x x x x$ & & & & 2 & 20 & & & & & $x x x x$ & & & \\
\hline & & $x x$ & $x x$ & & & $\widehat{x x x x}$ & 2 & $\frac{30}{45}$ & & & & & & & & \\
\hline & & & & & & $x x x x$ & & & & & & & & & & \\
\hline$\frac{\lambda \lambda \lambda \lambda}{x x}$ & & & & & & $\frac{1 \wedge A n}{X X X X}$ & 9 & 30 & & $\frac{x x x x}{x x}$ & & & & & & \\
\hline$\frac{x x x x}{x x}$ & & $x x$ & & & & \begin{tabular}{|l}
$X X X X$ \\
$X X X X$ \\
\end{tabular} & $\begin{array}{l}9 \\
9\end{array}$ & $\begin{array}{l}45 \\
70\end{array}$ & $\frac{x x}{x x}$ & & & & & & & $\frac{x x}{x x}$ \\
\hline $\begin{array}{l}X X X X X \\
X Y Y Y\end{array}$ & $x x$ & & & & & & $\frac{11}{11}$ & $\frac{20}{20}$ & & $\begin{array}{l}X X X X X \\
X Y Y Y\end{array}$ & & & & & & \\
\hline$\frac{x \times x x}{x x x}$ & & $x x$ & & & & & & $\frac{30}{45}$ & & & & & & & & \\
\hline$\frac{\hat{x} x \mathrm{x} x}{x}$ & $\frac{x}{x x}$ & & & & & & 11 & 70 & $\widehat{x x x x}$ & & & & & & & \\
\hline$\frac{x x x x}{x x x x}$ & $\frac{x x}{x x}$ & & & & & & 16 & $\begin{array}{l}20 \\
30\end{array}$ & & $\begin{array}{l}X X X X \\
X X X X X\end{array}$ & & & & & $x x$ & \\
\hline 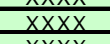 & & & & & & & $\frac{16}{16}$ & $\begin{array}{l}30 \\
45 \\
\end{array}$ & $x \times x x$ & & & & & & & \\
\hline$\frac{\lambda A \lambda \lambda}{X X X X}$ & & & & & & & $\begin{array}{c}16 \\
8\end{array}$ & $\begin{array}{l}10 \\
20\end{array}$ & $x \times x x$ & $x x x x$ & & & & & & \\
\hline$x x x x$ & & & & XXXX & & & 8 & 30 & & & & & & $x x x x$ & & \\
\hline & & & & $\mathrm{XXXX}$ & & & 8 & 70 & & & & & & $\overline{x X X X}$ & & \\
\hline$\frac{x x x x}{x x}$ & & & $\frac{x x}{x x}$ & $x x x x$ & & & $\begin{array}{l}17 \\
17\end{array}$ & 30 & & $\frac{x x x x}{x x x x}$ & & & $x x x x$ & $\frac{x x x x}{x x x x}$ & & \\
\hline$x x x x$ & $\frac{x x}{x y}$ & & yy & $y x y x$ & & & 17 & $\begin{array}{l}45 \\
70\end{array}$ & $\frac{x x x x}{x y x y}$ & & & & & $\overline{X Y X Y}$ & & \\
\hline$\frac{x x}{x x x x}$ & & & $\frac{x x}{x x}$ & 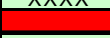 & & & $\frac{11}{6}$ & $\frac{10}{20}$ & & $x x x x$ & & & & $x \times x \times$ & & \\
\hline & $x x$ & & $x x$ & $x x x x$ & & & 6 & 30 & & $x x$ & & & $x X X X$ & $x x x$ & & \\
\hline$x x x x$ & & & $x x$ & $y x y y$ & & & 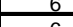 & & $\frac{x x x x}{x}$ & & & & & & & \\
\hline$x x x x$ & $x x$ & & $\frac{1 x}{x x}$ & $\lambda \Lambda \lambda \lambda$ & & & $\frac{0}{14}$ & 20 & & $x x x x$ & & & & & $\overline{x x}$ & \\
\hline$x=x x$ & & $x x$ & $x x x x$ & & & & 14 & & & & & & $x x x x$ & & & \\
\hline$\frac{x \times x x}{x x}$ & $x x$ & & & & & & $\begin{array}{l}14 \\
14\end{array}$ & $\begin{array}{l}45 \\
70\end{array}$ & $\begin{array}{l}X X X X \\
X X X X\end{array}$ & & & & & & & \\
\hline$x x$ & $x X X X$ & & & $x x x x$ & & & 4 & & & $x x$ & $x X X X$ & & & $x X X X$ & & \\
\hline & $x_{x}$ & & & $\frac{X_{X X X}}{Y Y Y Y}$ & & & 4 & 30 & & & $x x x x$ & & & $\frac{X_{X X X}}{Y Y Y Y}$ & & \\
\hline$x x$ & $x x$ & & & & $x x x x$ & & & $\frac{10}{20}$ & & $x x x x$ & & & & $x x x x$ & $x x x x$ & \\
\hline & $x x$ & & & YYYYY & & & $\frac{13}{12}$ & 30 & & & $x x$ & & & $\frac{X X X X}{Y Y Y Y}$ & & \\
\hline & $x x$ & & & & $x x x x$ & & 5 & 20 & & $x x x x$ & & & & $\lambda_{1}$ & $x$ & \\
\hline & $x x$ & & $x x x x$ & $x x$ & & & & & & & & & $x x x x$ & $x x x x$ & & \\
\hline$\frac{x x x x}{x x}$ & & & & $x X X X$ & & & $\begin{array}{l}5 \\
5\end{array}$ & $\begin{array}{l}45 \\
70\end{array}$ & $\frac{X X X X}{X X X X}$ & & & & & $x X X X$ & & \\
\hline & $\frac{X X X X}{x y y}$ & & $x x x x$ & & & & 3 & 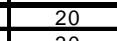 & & & $x x x x$ & & $x x x x$ & & & \\
\hline & $\frac{X_{X X X}}{Y Y Y Y}$ & & & & & & ]$^{3}$ & 30 & & & $x x x x$ & & & & & \\
\hline$\frac{x A}{X X X X}$ & & & $\frac{x x}{x x}$ & & & & 3 & $\begin{array}{l}45 \\
70\end{array}$ & $\begin{array}{l}\hat{A} X \wedge \wedge \\
X X X X\end{array}$ & & & & & & & \\
\hline & $x x x x$ & $x x$ & & & & & 18 & 20 & & & XXXX & & & & & \\
\hline$\overline{X X X X}$ & & & & & & & & & $y x y x$ & & & & & & & \\
\hline$x x$ & $x x$ & & & & & & 18 & 70 & 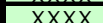 & & & & & & & \\
\hline
\end{tabular}


SRT-RPP-2003-00063

There is consistent disagreement between the predicted and the experimental results involving sodium oxalate at the $45^{\circ} \mathrm{C}$ storage temperature. For every sample that contains sodium oxalate at this temperature, the model predicts that it should be a major precipitant. The model also calls for carbonate as a major precipitant in these same samples. However, in every one of these samples (simulants 5, 6,8, and 17) the experimental results yield only sodium carbonate as a major precipitant. This is likely due to an overstatement of sodium carbonate solubility at $45^{\circ} \mathrm{C}$ in relation to sodium oxalate. Referring to Figure 4-5, one will notice the difference between the model's prediction of solubility and our experimental data at $45^{\circ} \mathrm{C}$. The experimental results for the evaporation and dissolution tests consistently show lower solubility in relation to what is predicted by the model at $45^{\circ} \mathrm{C}$. This overstatement of sodium carbonate solubility in the model in relation to sodium oxalate explains this difference that is seen in the precipitant data. The model predicts sodium oxalate and sodium carbonate will form simultaneously as major the precipitants. However, the experimental results consistently show sodium carbonate precipitating before sodium oxalate at $45^{\circ} \mathrm{C}$. Also, with in these same samples the opposite pattern is observed at $70^{\circ} \mathrm{C}$. As mentioned earlier the model predicts carbonate and oxalate as a precipitant. However, only the precipitation of sodium oxalate is verified by experimentation at this temperature, which is unlike the $45^{\circ} \mathrm{C}$ temperature where only carbonate was observed. These irregularities indicate that the oxalate predictions need to be improved. Oxalate is likely the cause of the irregularities because when oxalate is not present, the solubility observed during experimentation closely matches those predicted by the model.

Sodium sulfate is predicted as a likely precipitant in simulant 2 at the $45^{\circ} \mathrm{C}$ and $70^{\circ} \mathrm{C}$ storage temperatures. The model also predicts sodium sulfate has small possibility to precipitate in samples 1 and 9. Experimental results never yielded sodium sulfate precipitants in any of the samples at any storage temperature. The model needs to be adjusted so that sodium sulfate is not a precipitant.

The sulfate ion is a component of burkeite, which is a precipitant in both the model and experimentation. Burkeite is a major experimental precipitant in samples 1,2 , and 9 at every storage temperature. The model predicts burkeite precipitation in the same samples. However, there is consistent disagreement between the model and the experimental data involving the precipitation of burkeite at $20^{\circ} \mathrm{C}$. The model does not predict the precipitation of burkeite below $30^{\circ} \mathrm{C}$. Therefore, the model needs to be updated to include the behavior of burkeite down to $20^{\circ} \mathrm{C}$.

Additional discrepancies are found in the prediction of aluminum hydroxide. Within the $20^{\circ} \mathrm{C}$ storage temperature, the model predicts that simulants 8,11 , and 17 will precipitate aluminum hydroxide at $20^{\circ} \mathrm{C}$. For each of these samples there are no aluminum hydroxide solids found during experimentation. As discussed earlier, some of the simulants would not dissolve during dissolution and the remaining solids were filtered. These solids were from the $20^{\circ} \mathrm{C}$ matrix samples. Upon XRD analyses these samples were discovered to contain aluminum hydroxide, almost exclusively. However, none of these samples that contained the discrepancy regarding aluminum solids (Samples 8 , 11, and 17) needed to be filtered. Therefore, the discrepancies noticed here could not be attributed to filtering aluminum hydroxide from the simulants before evaporation. Consequently, it must be concluded that the model understates the solubility of aluminum hydroxide relative to the other components.

According to the model and experimental data, sodium nitrate is not a major precipitant often. There is good agreement between the model and experimental data in the cases where sodium nitrate is identified as a precipitant. However, the model seems to overstate the solubility of sodium nitrate at the higher temperatures. In samples 5, 3, and 18 the experiments show the formation of sodium nitrate. This is not consistent with the model.

\subsection{CONCLUSIONS}

The single and double component solubility test give an insight to the performance of the components during the multi-component solubility test. These tests revealed that sodium carbonate and sodium oxalate as the least soluble components. This provides evidence to why carbonate and oxalate are the most prominent precipitants during evaporation. 
SRT-RPP-2003-00063

The evaporation and dissolution curves differ most at $30^{\circ} \mathrm{C}$. The inconsistencies shown between the two trends at $30^{\circ} \mathrm{C}$ are attributed to the transition between the decahydrate and monohydrate form of sodium carbonate. The dissolution tests lack heating necessary to initiate this transition. The results of the evaporation test agree with model predictions that consistently show an increase in solubility at $30^{\circ} \mathrm{C}$. Neither the dissolution tests nor the single- and double-component solubility tests exhibit this increase. Therefore, if dissolution experimentation had included brief heating above the transitional temperature, it is likely that the dissolution curves would more closely match those of the evaporation and modeling curves. Furthermore, when the $30^{\circ} \mathrm{C}$ temperature data is removed from the evaporation test, the solubility trends (the shapes of the curves) of the evaporation and dissolution experiments show better agreement.

Evaporation experiments agree with the solubility trends of the model at most matrix temperatures. Both trends exhibit a sharp increase in solubility at the $30^{\circ} \mathrm{C}$ matrix. However, evaporation and modeling trends differ at the $45^{\circ} \mathrm{C}$ matrix. It is anticipated that a broad adjustment of the solubility data must be made to the model at the $45^{\circ} \mathrm{C}$ storage temperature. The model consistently predicts a solubility that is higher than what is observed during experimentation. This general overstatement is believed to be an overstatement in the solubility of sodium carbonate related to the transition from decahydrate to monohydrate. In simulants where sodium carbonate and sodium oxalate are both present, the model consistently predicts both as precipitants at $45^{\circ} \mathrm{C}$. During experimentation only sodium carbonate is detected. Also with in these same samples the opposite pattern is observed at $70^{\circ} \mathrm{C}$. Again the model predicts carbonate and oxalate as a precipitant. However at this temperature only the precipitation of sodium oxalate is verified by experimentation, which is unlike the $45^{\circ} \mathrm{C}$ temperature where only carbonate was observed. These irregularities indicate a possible flaw in the model. The flaw may by associated with sodium oxalate because when oxalate is not present the solubility values of the model and experimentation agree.

Also, minor adjustments in the model must be made to include the precipitation of Burkeite at $20^{\circ} \mathrm{C}$. The instances where burkeite precipitates experimentally never agree with those that are predicted in the model at $20^{\circ} \mathrm{C}$. Good agreement occurs between the model and experimental data for the other temperatures. Therefore the model needs to be adjusted to include the precipitation of burkeite at $20^{\circ} \mathrm{C}$. Also adjustments should be made to the solubility of sodium sulfate in the model. Although the model predicted sodium sulfate formation for several tests, the experiments never yielded sodium sulfate as a precipitant.

Additionally there is excellent agreement, between the model's predicted solubility and the solubility values obtained through experimentation at the $70^{\circ} \mathrm{C}$ matrix. This is true for any simulant that does not contain sodium oxalate. For simulants that contain sodium oxalate, the model consistently predicts a solubility that is higher than what is observed through experimentation. 
WSRC-TR-2003-00148, Rev. 0

SRT-RPP-2003-00063

\subsection{ATTACHMENTS}

Attachment 1. Physical Property Data

\begin{tabular}{|c|c|c|c|c|c|c|c|c|c|c|c|}
\hline \multicolumn{6}{|c|}{ 20C Storage Temperature } & \multicolumn{6}{|c|}{ 30C Storage Temperature } \\
\hline Sample \# & $\mathrm{pH}$ & $\begin{array}{l}\text { Density } \\
20 \mathrm{C}\end{array}$ & $\begin{array}{l}\text { Density } \\
50 \mathrm{C}\end{array}$ & $\begin{array}{l}\text { Visc. (cP) } \\
20 \mathrm{C}\end{array}$ & $\begin{array}{l}\text { Visc. (cP) } \\
50 \mathrm{C}\end{array}$ & Sample \# & $\mathrm{pH}$ & $\begin{array}{l}\text { Denisty } \\
20 \mathrm{C}\end{array}$ & $\begin{array}{l}\text { Density } \\
50 C\end{array}$ & $\begin{array}{l}\text { Visc. (cP) } \\
20 \mathrm{C}\end{array}$ & $\begin{array}{l}\text { Visc. (cP) } \\
50 \mathrm{C}\end{array}$ \\
\hline 1 & 12.44 & 1.366 & 1.341 & 5.91 & 2.56 & 1 & 13.16 & 1.331 & 1.311 & 5.36 & 2.35 \\
\hline 2 & 13.00 & 1.268 & 1.157 & 2.94 & 1.35 & 2 & 13.44 & 1.330 & 1.313 & 4.43 & 2.05 \\
\hline 3 & 12.68 & 1.426 & 1.401 & 5.82 & 2.63 & 3 & 13.39 & 1.428 & 1.409 & 6.02 & 2.73 \\
\hline 4 & 12.86 & 1.296 & 1.274 & 4.10 & 1.89 & 4 & 13.34 & 1.226 & 1.207 & 2.70 & 1.38 \\
\hline 5 & 11.74 & 1.158 & 1.133 & 1.97 & 1.06 & 5 & 13.28 & 1.295 & 1.277 & 5.38 & 2.32 \\
\hline 6 & 13.09 & 1.275 & 1.265 & 4.27 & 2.06 & 6 & 13.45 & 1.253 & 1.234 & 3.73 & 1.90 \\
\hline 7 & -.- & --- & --- & $\ldots$ & --- & 7 & $-\ldots$ & --- & $-\ldots$ & --- & ---- \\
\hline 8 & 12.07 & 1.154 & 1.138 & 2.09 & 1.12 & 8 & 12.98 & 1.246 & 1.229 & 4.06 & 1.89 \\
\hline 9 & 11.60 & 1.143 & 1.127 & 1.89 & 1.00 & 9 & 13.20 & 1.355 & 1.331 & 9.91 & 3.38 \\
\hline 10 & $-\ldots$ & $\ldots$ & --- & $-\ldots$ & --- & 10 & $-\ldots$ & --- & -.- & --- & --- \\
\hline 11 & 12.56 & 1.160 & 1.144 & 2.12 & 1.15 & 11 & 13.17 & 1.319 & 1.304 & 9.78 & 3.18 \\
\hline 12 & & & & & & 12 & & & & & \\
\hline 13 & 12.17 & 1.153 & 1.136 & 1.82 & 1.02 & 13 & 13.10 & 1.243 & 1.226 & 3.32 & 1.62 \\
\hline 14 & 13.17 & 1.282 & 1.259 & 3.58 & 1.72 & 14 & 13.57 & 1.334 & 1.311 & 6.33 & 3.11 \\
\hline 15 & $\ldots$ & $\ldots$ & $\ldots$ & $\ldots$ & $\ldots$ & 15 & $\ldots$ & $\ldots$ & $\ldots$ & $\ldots$ & $\ldots$ \\
\hline 16 & 13.06 & 1.304 & 1.175 & 2.87 & 1.35 & 16 & 13.71 & 1.316 & 1.296 & 5.15 & 3.26 \\
\hline 17 & \begin{tabular}{|l} 
insf. amt. \\
\end{tabular} & 1.223 & insf amt. & 3.05 & & 17 & 13.26 & 1.257 & 1.241 & 4.23 & 1.98 \\
\hline 18 & 13.03 & 1.306 & 1.283 & 4.13 & 1.92 & 18 & 13.51 & 1.34 & 1.319 & 5.45 & 2.42 \\
\hline \multicolumn{6}{|c|}{$45 \mathrm{C}$ Storage Temperature } & \multicolumn{6}{|c|}{ 70C Storage Temperature } \\
\hline Sample \# & $\mathrm{pH}$ & \begin{tabular}{|l} 
Density \\
$20 \mathrm{C}$
\end{tabular} & $\begin{array}{l}\text { Density } \\
50 \mathrm{C}\end{array}$ & $\begin{array}{l}\text { Visc. (cP) } \\
20 \mathrm{C}\end{array}$ & $\begin{array}{l}\text { Visc. (cP) } \\
50 \mathrm{C}\end{array}$ & Sample \# & $\mathrm{pH}$ & $\begin{array}{l}\text { Denisty } \\
20 \mathrm{C}\end{array}$ & $\begin{array}{l}\text { Density } \\
50 C\end{array}$ & $\begin{array}{l}\text { Visc. (cP) } \\
20 \mathrm{C}\end{array}$ & $\begin{array}{l}\text { Visc. (cP) } \\
50 \mathrm{C}\end{array}$ \\
\hline 1 & -.- & -.- & --.- & --- & -.- & 1 & 12.87 & 1.332 & 1.316 & 5.40 & 2.29 \\
\hline 2 & 13.49 & 1.314 & 1.295 & 4.14 & 1.91 & 2 & 12.98 & 1.324 & 1.303 & 3.96 & 1.76 \\
\hline 3 & 13.14 & 1.330 & 1.310 & 3.31 & 1.76 & 3 & 13.05 & 1.434 & 1.403 & 6.58 & 2.80 \\
\hline 4 & $\ldots$ & -.- & --- & $\ldots$ & $\ldots$ & 4 & 12.90 & 1.255 & 1.239 & 3.18 & 1.56 \\
\hline 5 & 13.05 & 1.228 & 1.212 & 3.13 & 1.58 & 5 & 12.86 & 1.316 & 1.300 & 3.38 & 1.97 \\
\hline 6 & 13.40 & 1.239 & 1.223 & 3.35 & 1.66 & 6 & 13.20 & 1.291 & 1.275 & 4.90 & 2.21 \\
\hline 7 & $\ldots$ & $\ldots$ & $\ldots$ & $\ldots$ & $\ldots$ & 7 & $\ldots$ & $\ldots$ & $\ldots$ & $\ldots$ & $\ldots$ \\
\hline 8 & 12.76 & 1.163 & 1.147 & 2.20 & 1.18 & 8 & 12.82 & 1.240 & 1.226 & 3.88 & 1.90 \\
\hline 9 & 12.96 & 1.187 & 1.172 & 2.45 & 1.32 & 9 & 13.26 & 1.365 & 1.353 & 8.55 & 3.08 \\
\hline 10 & 13.40 & 1.224 & 1.204 & 2.47 & 1.34 & 10 & --- & $-\cdots$ & --- & --- & --- \\
\hline 11 & 13.00 & 1.179 & 1.162 & 2.36 & 1.26 & 11 & 13.21 & 1.321 & 1.304 & 4.61 & 2.02 \\
\hline 12 & 13.49 & 1.251 & 1.231 & 2.96 & 1.71 & 12 & --- & --- & --- & --- & --- \\
\hline 13 & $-\cdots$ & -.- & --- & $\ldots$ & $-\ldots$ & 13 & 12.88 & 1.234 & 1.218 & 3.08 & 1.54 \\
\hline 14 & 13.41 & 1.265 & 1.248 & 3.99 & 1.91 & 14 & 13.58 & 1.344 & 1.328 & 5.29 & 2.44 \\
\hline 15 & 13.32 & 1.202 & 1.185 & 2.27 & 1.23 & 15 & -.- & $\ldots$ &.-- & $\ldots$ & $\ldots$ \\
\hline 16 & 13.52 & 1.252 & 1.256 & 5.07 & 2.40 & 16 & 13.44 & 1.325 & 1.315 & 5.15 & 2.20 \\
\hline 17 & 12.85 & 1.194 & 1.176 & 2.69 & 1.36 & 17 & 12.86 & 1.295 & 1.279 & 5.66 & 2.04 \\
\hline 18 & 13.43 & 1.226 & 1.208 & 2.58 & 1.33 & 18 & 13.32 & 1.369 & 1.349 & 6.38 & 2.85 \\
\hline
\end{tabular}

